\title{
MITO E FILOSOFIA
}

\section{Marcelo Perine}

Pontifícia Universidade Católica de São Paulo

m.perine@ig.com.br

RESU M 0: 0 artigo trata das relações entre mito e filosofia enquanto formas do discurso humano. A análise filosófica da narrativa mítica a partir do modelo metafórico e a compreen são da consciên cia mítica, como forma originária da presença do ser humano no mundo, revelam o mito como sabedoria, pela qual os grupos humanos garantiram sua sobrevivência e identidade e na qual formulam o sentido de sua existência.

Palavras-chave: Mito, filosofia, narrativa, metáfora, sabedoria.

Também aquele que ama o mito é, de certo modo, filósofo.

Aristóteles, M etafísica, A 2, 982 b 18

0 interesse pelos mitos, hoje em dia, invade quase todos os campos do saber. Etnólogos, sociólogos, culturalistas, historiadores das religiões, dasidéias, juristas e economistas, arqueólogos, filólogos e lingüistas, cientistas políticos e especialistas em marketing, psicólogos e psicanalistas, teólogos e filósofos - a lista poderia enveredar também por todos os tipos de esoterismos - , todos parecem ter alguma coisa a dizer e, eventualmente, a aprender dos mitos. M as esse interesse não se restringe aos especialistas. 0 ser humano mais comum, o telespectador, o leitor dos jornais diários, o trabalhador, o consumidor, o crente e o ateu, o fiel de uma religião ou de uma seita, bem como o agnóstico indiferente, de algum modo e em número sempre maior, estabel ece relações mais ou menos interessadas com essas realidades profundamente humanas que são os mitos. Especialistas ou não, o fato é que o ser humano não vive, porque não pode viver, sem mitos. 
0 objetivo da presente reflexão é, talvez, demasiadamente modesto diante da complexidade e do alcance da problemática subjacente ao título "M ito e Filosofia". D ada a universalidade e a atualidade do fenômeno, pretendo apenas esboçar algumas perspectivas para a sua compreensão filosófica. É certo que essa compreensão não pode ignorar as perspectivas de outros campos do saber. De fato, ela as pressupõe, em grande parte, mas não se reduz a elas. $\mathrm{N}$ a verdade, a filosofia, além do privilégio histórico de ter sido a primeira tentativa de compreensão do mito, tem consciência, desde a sua origem, do seu parentesco com ele. A filosofia, se não filha, é, pelo menos, irmã mais nova do mito e estabeleceu desde 0 seu berço uma fascinante relação de amizade e confronto com esse irmão mais velho.

0 alvorecer da filosofia na tradição ocidental mistura as suas luzes e sombras com as do mito que a precedeu na odisséia da humanidade. Com efeito, uma das proposições fundadoras da filosofia ocidental, atribuída a Tales de Mileto, afirma que "tudo está cheio de deuses", 1 o que aponta para a quase ausência de fronteiras entreo pensamento filosófico nascente e o pen samento mítico então já consolidado na mentalidade religiosa dos gregos. ${ }^{2}$ Por outro lado, o obscuro H eráclito de Éfeso, pouco posterior a Tales, sustenta, no famoso fragmento 32, que "o uno, o único sábio, não quer e também quer ser chamado Zeus", ${ }^{3}$ o que significa que

quer ser chamado assim, porque na verdade é o que se venera sob aquele nome; mas também não quer ser chamado assim, porque a este nome ligam-se representações antropomórficas que não convêm àquele ser primordial, isto é, porque é uma designação inadequada. ${ }^{4}$

Além do privilégio decorrente do parentesco com o mito, a prioridade da filosofia na compreensão do fenômeno é também cronológica. De fato, muito antes do nascimento de uma filosofia da mitologia ${ }^{5}$ ou de uma ciência da mitologia, que pode ser fixada na metade do século XIX da nossa era, já no século VI a.C., 
Xenófanes de Colofônia ${ }^{6}$ lançou as bases da primeira crítica sistemática da mentalidade religiosa dos gregos, abrindo caminho para a tentativa platônica de sistematizar e de compreender o lugar do mito no saber ena vida humana. M as também aqui a relação de atração e repulsão entre a filosofia e o mito fica patente. Se, por um lado, a partir do livro II da República, Platão pretende acompanhar "em lógos" a formação de uma cidade, ${ }^{7}$ o que parece exigir o mesmo tipo de discurso que justificará o banimento da cidade ideal de grande parte da mitologia dominante, sedimentada na obra dos poetas, H omero em particular; por outro lado, recorrefreqüentemente ao mito em vários momentos da sua obra e também cria alguns mitos, ${ }^{8}$ não só porque a sua filosofia é profundamente religiosa e grandemente devedora das concepções órfico-pitagóricas, ${ }^{9}$ mas também porque reconhece que uma sociedade, mesmo governada por filósofos, tem necessidade da única realidade que lhe pode dar coesão, isto é, um saber partilhado e implícito pelo qual a comunidade mantém a sua identidade ea expressa nas suas opiniões, nos seus cantos, nos seus relatos e nas suas histórias. ${ }^{10}$

A compreensão filosófica do mito põe, fundamentalmente, a questão do seu sentido. Esse modo de compreender o mito se diferencia das tentativas de aproximação do fenômeno feitas pelas ciências humanas, como a etnologia, a sociologia, a antropologia cultural, e distingue-se também das interpretações religiosas e esotéricas do mito. 0 pressuposto fundamental da compreensão filosófica do mito é que ele, antes de tudo, é palavra ou, o que é o mesmo, uma das formas do discurso humano. Fica, portanto, claro, desde logo, que o estereótipo oposição irreconciliável entre mythos e lógos é sem fundamento para uma genuína compreensão filosófica do fenômeno. Prova disso, segundo Clémence Ramnoux, é o fato de que, pelo menos na assim chamada era arcaica da Grécia, o mito, no sentido de "narrativa sagrada", é praticamente equivalente a um lógos qualificado de hieros. É certo que o lógos, assumindo progressivamente, na era clássica, o sentido de "discurso regrado" e, a partir daí, o de "raciocínio" que remete à "razão", ao "cál culo" 
e à "medida", assumiu um uso filosófico que tendia a se opor ao mito como narrativa sagrada. ${ }^{11}$ Entretanto, antes de chegar a uma oposição, mythos e lógos estiveram unidos, pelo menos segundo a antiga etimologia que identifica mythos e palavra.

A evolução semântica de mythos parece, portanto, apontar mais para aproximações do que para oposições com o lógos. A etimologia da palavra mythos divide os especialistas até os dias de hoje. Há os que propõem uma derivação de myo, que significa "fechar"; outros fazem derivar de myéo, que significa "iniciar", "instruir", de on de vem também "mistério". Há ainda os que levantam a hipótese de uma ligação com a exclamação mû, da qual fazem também derivar os vocábulos myo e myéo, supondo que daquele lamento teriam nascido termos que indicam "emudecer" e "fazerse sentir". A explicação que recolhe maior adesão entre os especialistas remete a palavra mito a uma raiz indoeuropéia meudh ou mudh, com significados diversos, mas aproximados de "recordarse", "aspirar", "preocupar-se". Essa etimologia levaria a pal avra grega mythos ao significado fundamental de "pensamento", o que éconvalidado pelo uso dos termos mytholomai, muythologeo, mythologia em É squilo, Sófocles e H omero. Em comparação com o campo semântico do vocábulo epos, que também significa "palavra", "canto", de onde vem "épica", o campo semântico do vocábulo mythos, no sentido geral de "palavra formulada", inclui os seguintes sentidos: notícia, mensagem, conto, estória, boato, narração à qual se dá crédito, fábula, saga, lenda. ${ }^{12}$

Quando se trata de perguntar sobre o sentido do mito, a resposta pode ser buscada de três modos. ${ }^{13} 0$ primeiro busca 0 sentido do mito na própria mitologia. Esse modo de interpretar 0 mito, cujo representante mais conhecido é Claude Lévi-Strauss, entende que a mitologia deve ser considerada como uma "mitológica", isto é, como um sistema coerente, ordenado e fechado de mitos e de crenças diversas, que não pretende dizer "outra coisa" além da realidade, mas apenas especular sobre suas virtualidades latentes. D ado que o mito quer simplesmente dizer "a mesma coisa" 
e não "outra coisa" além da realidade, essa interpretação foi também chamada de "interpretação tautegórica" do mito. ${ }^{14} 0$ segundo modo de interpretação busca o sentido do mito fora ou além da mitologia, numa tentativa de despir o mito de sua roupagem fabulosa para encontrar outra coisa diferente do que ele diz. Essa interpretação é chamada de "alegórica" (do grego állos, outro; agoreúein, dizer), justamente porque busca um sentido escondido sob o sentido imediato, o qual é considerado inaceitável. ${ }^{15}$ Sob o nome de hupónoia, cujo sentido primeiro é "suspeita" ou "conjectura", essa interpretação aparece muito cedo na Grécia e seus mais famosos representantes foram os pitagóricose o estóicos. ${ }^{16} 0$ terceiro modo busca o sentido do mito através da mitologia. Esse modo foi inaugurado pelos neoplatônicos, na antigüidade, e encontra em Paul Ricoeur um dos seus mais conhecidos representantes atuais. ${ }^{17}$ Para essa interpretação, o mito contém um elemento indizível que o discurso racional não pode enunciar, e, por isso, ela é também conhecida como "interpretação simbólica" ou "metafórica" do mito. ${ }^{18}$

Para a compreensão filosófica do mito vale a pena considerar um pouco mais detidamente o primeiro e o terceiro modos de buscar o sentido do mito. Esses dois modos reconhecem no mito uma forma de discurso e o situam, portanto, no campo da lingüística. 0 primeiro o situa segundo o model o estrutural, procedente da fonologia e da semântica estrutural, mas acentua a textura sintática do mito; 0 segundo o situa segun do o model o metafórico, que privilegia o jogo interno dos conteúdos semânticos.

C laude Lévi-Strauss, ${ }^{19}$ o mais ilustre representante do modelo estrutural de interpretação do mito, considera a mitologia como a atuação de uma espécie de lógica própria da mente humana, que só pode ser entendida recorrendo aos pressupostos principais de um model o estrutural de análise da linguagem.

0 modelo de análise estrutural da linguagem foi elaborado principalmente por Ferdinand de Saussure (1857-1913), pelos estruturalistas da escola de Praga e pelos formalistas russos. ${ }^{20}$ Segundo esse modelo, a lingüística só deve levar em conta as regras do jogo 
lingüístico, não os acontecimentos da linguagem, o que implica, portanto, uma oposição entre língua e palavra. U ma segunda característica desse model o é que uma teoria estrutural da língua só atenta para os estados de sistema num momento dado, isto é, só considera a constituição sincrônica desse sistema e não as suas mudanças, a sua história, a sua diacronia. Em terceiro lugar, a análise estrutural só se interessa no sistema da língua pelas relações de oposição e de combinação entre os elementos, isto é, a "forma" e não a "substância", tanto semântica como fonológica. Finalmente, para o modelo estrutural, o sistema deve ser considerado um conjunto fechado sobre si mesmo, sem referência à realidade, nem à psicologia eà sociologia dos locutores.

Essa interpretação apresenta al gumas vantagens. Em primeiro lugar está o fato de considerar o mito, enquanto relato, como pertencendo ao conjunto das estruturas semiológicas. Em segundo lugar, o sistema das oposições e das combinações que reina sobre 0 domínio semiológico é encarado no seu caráter formal, enquanto estruturas para pensar o mundo, as quais servem tanto para marcar as diferenças e continuidades já existentes na natureza como para introduzir descontinuidades indispensáveis ao trabalho da inteligência. Em terceiro lugar, é positivo o fato de apontar para 0 funcionamento absolutamente inconsciente das regularidades que asseguram o caráter lógico do sistema. N esse sentido, não só écorreto afirmar que a estrutura do mito reflete a estrutura do espírito humano, mas podese até mesmo dizer que o mito não é falado pelos homens, mas, antes, habitado por eles que, como falantes, só exercem sobre ele o domínio aparente de todos os falantes sobre os efeitos de sentido dos sistemas semiológicos. ${ }^{21} \mathrm{C}$ ontudo, a questão que se pode levantar para o modelo estrutural de interpretação do mito éa seguinte: pode-se eliminar do mito a sua intenção, isto é, a sua pretensão de dizer algo sobre a realidade?

0 ponto de partida do modelo metafórico ou simbólico de interpretação do mito é o seguinte: a metáfora é sempre uma transferência de sentido. ${ }^{22} 0$ ra, essa transferência de sentido que 
define a metáfora não é uma propriedade da estrutura da linguagem, mas situa-se no campo do discurso propriamente dito. Portanto, éo enunciado, enquanto ato discursivo, que, por assim dizer, carrega o sentido e a referência. Segundo esse modelo, o mito deve ser situado ecompreendido no interior de uma semântica, que se refere às unidades de discurso, isto é, os enunciados, e não de uma semiótica, que se ocupa unicamente das unidades da língua.

U $\mathrm{m}$ ponto fundamental para entender o modelo metafórico de interpretação do mito é o seguinte: nós constatamos que a transferência de sentido é um procedimento normal da língua. Porém, antes mesmo de encontrarmos metáforas na nossa língua, que são procedimentos retóricos, existe o que podemos chamar de "processo metafórico", ligado a uma distinção já feita por Saussure no mecanismo da língua. Esse mecanismo implica dois tipos de combinação entre os signos: o primeiro tipo de combinação, de caráter sintagmático, repousa sobre a ordem de sucessão dos signos na mesma cadeia verbal. Trata-se, portanto, de uma conexão de signos, por assim dizer, na presença uns dos outros. 0 segundo tipo de combinação de signos, de caráter paradigmático, funda-se nas relações de semel hança constitutivas da esfera de associação na qual eu me situo à medida que meu discurso avança. $\mathrm{Na}$ dinâmica do discurso, eu tenho, a cada instante, a possibilidade de escolher entre todas as palavras que poderiam entrar no mesmo lugar do discurso. Porém, ao escolher uma palavra para ocupar um determinado lugar no discurso, ela exclui todas as outras desse lugar, dando-se assim uma relação entre os termos não mais na presença uns dos outros, mas na ausência uns dos outros. Pois bem, a primeira série de combinações de termos traduz o princípio das concatenações sintáticas da linguagem; a segunda traduz o princípio das concatenações semânticas. No plano do discurso, à primeira série de combinações corresponde o procedimento de metonímia, isto é, 0 procedimento retórico que consiste em designar uma coisa com o nome de outra, tomando o signo pela coisa significada. A segunda série de combinações funda-se sobre a semelhança, e, no plano do 
discurso, corresponde ao que a retórica clássica chama de metáfora, isto é, a transferência do sentido direto das pal avras para um sentido figurado, em virtude de uma comparação tácita. A ssim, as metáforas da nossa linguagem são expressões de um processo subjacente a todas as operações da linguagem, que é, justamente, chamado de processo metafórico. $N$ esse sentido, a metáfora não éalgo de excepcional, mas liga-se a um procedimento fundamental da linguagem.

U m segundo ponto importante para entender a compreensão metafórica do mito é que o problema específico do mito está relacionado ao problema do sentido múltiplo, isto é, da polissemia: as palavras da linguagem ordinária têm mais de uma significação. A polissemia não é uma fragilidade da linguagem, mas uma condição do seu funcionamento: para dizer a variedade infinita da nossa experiência, uma linguagem unívoca deveria ser infinita. A polissemia constitui, por assim dizer, a base natural do fenômeno particular de transferência de sentido que nós chamamos metáfora: a metáfora éal go muito mais radical do que um simples procedimento retórico. Segundo Paul Ricoeur, podese dizer que existe uma "metafórica" fundamental que preside à constituição dos campos semânticos ou, até mesmo, que a metáfora é o processo constitutivo dos campos semânticos. A distinção entre sentido próprio e sentido figurado, que caracteriza a metáfora retórica, já é uma distinção segunda ou posterior relativamente ao fato de ambos, isto é, o sentido próprio e o sentido figurado dos termos, pertencerem ao mesmo campo semântico.

Em terceiro lugar, observe-se que a passagem da polissemia das palavras ao caráter simbólico do discurso se dá porque, quando utilizo uma palavra que tem várias significações, eu não utilizo todas as suas potencial idades, mas apenas uma parte da sua significação. 0 resto da sua significação não desaparece no momento em que eu escolho uma palavra e a situo no interior de um enunciado, mas fica como que inibido e paira ao redor da palavra. Aí reside a possibilidade do jogo de palavras, da poesia, da linguagem simbólica. 
Há, portanto, três pontos importantes para se entender 0 funcionamento da linguagem simbólica: em primeiro lugar, 0 processo metafórico geral da linguagem; em segundo lugar, o fenômeno do sentido múltiplo ou polissemia e, finalmente, a estrutura contextual que, em vez de fixar como que uma pauta única ou um único alvo para o discurso, instaura a polifonia no nível do discurso. 0 caráter simbólico implícito ao mito repousa sobre essa arquitetura de significações da qual só uma teoria da linguagem considerada como discurso e não somente como sistema de signos pode dar conta. Pois bem, é no âmbito de uma teoria metafórica que se pode pôr a questão da inten ção significante do mito. ${ }^{23}$

Se o mito éum discurso ou uma narração, isto é, um conjunto de enunciados que carrega sentido e referência, é preciso admitir que 0 mito diz algo sobre algo. É esse dito do dizer que devemos agora descobrir. A poiados em M ircea Eliade, ${ }^{24}$ adotamos a hipótese de que o mito é, fundamentalmente, um "relato das origens" e que, enquanto tal, tem uma função de instauração: só há mito se o acontecimento fundador não tem lugar na história, mas num tempo antes da história. 0 mito diz sempre como nasceram as coisas, as instituições, as regras etc.

A essa definição do mito como relato das origens ligam-se três corolários..$^{25} 0$ primeiro referese à relação das "representações" míticas com a função de instauração. A função de instauração é fixa em todos os mitos, enquanto as representações são variáveis. Isso explica por que a função de instauração pode ser assumida por seres sobrenaturais de diferentes naturezas: deuses, heróis, semideuses, mensageiros etc. No esquema da história das origens, as "figuras" ou "representações" às quais se recorre para formular o discurso têm uma função segunda com relação à função de instauração do discurso mítico. Essas figuras são o que, literariamente, se chama de dramatis personae, e são apreendidas pelo que fazem e não pelo que são. No caso do relato mítico, essas figuras não são mais do que uma variação da função instauradora. Aqui pode ocorrer uma expansão figurativa ou representativa do universo 
mítico, no sentido de que as figuras podem adquirir autonomia com relação à história das origens, de modo que o universo mítico acabe apresentando uma proliferação de formas do sobrenatural: sobrenatural meio-divino, meio-humano, heróis, filhos de reis, façanhas etc.

O segundo corolário da definição do mito como relato das origens concerne à função prática do mito ou às suas implicações institucionais. M uitas escolas antropológicas destacaram a estreita ligação entre mito e rito. 0 mito funda o rito estabelecendo paradigmas de ação. Por exemplo, no Antigo Testamento há um laço entre o relato da criação e o ritual do Ano N ovo no curso do qual o relato era lido e o rei entronizado. Esse laço deve ser compreendido no seu princípio: é na medida em que o mito institui a relação entre o tempo histórico com o tempo primordial que a narração das origens toma o valor de paradigma para o tempo presente, como que dizendo: eis como era no princípio e como continua sendo agora! Pela sua intenção significante fundamental, o mito pode ser repetido, reativado no rito. A qui também pode ocorrer uma expansão pragmática que levará o rito a adquirir autonomia, de modo a parecer que é o rito que sustenta o mito.

0 terceiro corolário refere-se às implicações psicológicas do mito. É possível dar conta dos valores emocionais do sagrado a partir da função instauradora do relato das origens. A ligação entre 0 tempo histórico e o tempo primordial desenvolve efeitos próprios, descritos por Rudolf 0 tto no seu famoso estudo 0 Sagrado: ${ }^{26}$ ele punha na origem do sagrado o sentimento ambivalente de temor e de amor com o qual o homem mítico se volta para o tremendum fascinosum. Esse estilo emocional próprio ao sagrado é compreensível se consideramos que pelo relato das origens o homem emerge do tempo histórico na direção do tempo fundamental. Essa espécie de contemporaneidade emocional com as origens é estabelecida ao mesmo tempo pelo ato de relatar e pela reativação do sentido do relato na ação ritual. Pode-se falar de uma reativação emocional como o complemento do elemento representativo e do elemento 
pragmático dos quais falamos acima: "viver segundo o mito" é deixar de existir unicamente na vida cotidiana ou, mais exatamente, é ativar na vida cotidiana, pela recitação e pelo rito, o que se pode chamar de núcleo mítico-poético da existência humana.

Antes de concluir esta reflexão com uma breve consideração sobre mito e sabedoria, quero chamar a aten ção para um fenômeno constitutivo da consciência humana, que é a consciência mítica. Podemos distinguir, na unidade do mesmo sujeito, três níveis de consciência: 0 nível empírico, o nível racional e o nível teórico. ${ }^{27}$ Por consciência entendese aqui a presença do sujeito ao todo da sua experiência como ser racional no mundo. 0 nível empírico da consciência se define pela presença do sujeito ao aqui e agora da sua experiência sensível e emocional. A consciência mítica, forma do existir para si do ser humano no nível empírico, é a forma originária da presença do ser humano no mundo e o ponto de partida da sua afirmação como sujeito. Segundo G eorges G usdorf, a consciência mítica é a forma espontânea de ser no mundo. ${ }^{28} E$ a primeira forma de conhecimento que o ser humano tem de si e do mundo, que já implica, embora de forma não percebida reflexivamente, uma separação do ser humano com relação ao seu mundo circundante. 0 ra, essa ruptura original, que coincide com o nascimento da própria humanidade, é o que cria, ao mesmo tempo, 0 sentimento da separação e a nostal gia da unidade rompida. A ruptura do horizonte imediato éo equivalente filosófico do que, do ponto de vista teológico, chama-se pecado original. ${ }^{29}$

0 relato mítico surge, então, como expressão do sentimento de separação e como tentativa de restaurar a unidade e a inocência perdidas. Eis por que todo mito, como sustenta Mircea Eliade, é sempre um relato das origens com finalidade instauradora. A forma de consciência que o produz apreende o tempo como um agora permanente que, de algum modo, permanece grudado ao tempo das origens. 0 tempo não aparece como sucessão linear, progressiva, mas como continuidade cíclica de um tempo único, que está todo presente em cada momento vivido. Não existe ainda a noção de 
história, embora o mito, ao se traduzir em relato, contribua para o surgimento de uma forma de consciência que apreende o tempo como história. Para a consciência mítica, o tempo não é mais que um prolongamento do grande tempo primordial. Esse tempo das origens é cel ebrado na festa, que é um tempo sagrado, no qual se comemora a "repetição do ato cosmogônico", 30 de modo que a consciência mítica apreende 0 tempo, não como progresso, mas como eterno retorno.

Também a apreensão do espaço, para a consciência mítica, corresponde ao sentimento de separação e de nostal gia das origens. 0 espaço circundante é, todo ele, de alguma forma, sagrado. 0 templo e o altar são uma espécie de espaço eminente no qual todo o espaço cósmico está presente. 0 espaço, para a consciência mítica, é o reflexo do espaço cósmico, do qual o homem está se separando, mas no qual ele se encontra gratuitamente, como que dado a si mesmo. Como diz Georges Gusdorf:

0 homem se encontra associado, por uma participação necessária, à liturgia cósmica. Se não se cumprem corretamente os ritos, a lua não mais se elevará, não haverá mais primavera, perder-se-á a colheita, a caça será infrutuosa, a fome e a enfermidade ocasionarão a morte dos homens e as mulheres serão estéreis. 0 homem primitivo não pode começar nada. Mas, para ele, tudo está sempre por começar. ${ }^{31}$

A função da festa no tempo eno espaço da consciência mítica consiste em intensificar a vivência do sagrado, integran do a comunidade, de maneira eminente, no grande tempo e espaço das origens através do rito. Essa expansão pragmática do mito, que é o rito, mostra a estreita ligação entre a atitude vivida e a narração. A própria perpetuação efidelidade ao rito exigem que se narre o mito. É por isso que "pertence à essência do mito que se o relate sempre denovo". ${ }^{32}$ Confirma-se, assim, o pressuposto que assumimos nesta exposição, segundo o qual o mito é sempre uma forma de discurso, uma palavra queencarna um sentido vivido, não como algo separado 
dele, mas como uma invocação da vida, como uma palavra que penetra a realidade e a "maneja segundo as suas próprias leis". ${ }^{33}$

0 mito, na sua dupla dimensão de narração e experiência vivida, apresenta-se como uma sabedoria de vida, um saber que justifica o ser humano e o mundo, fundando-os no intemporal e dando-thes um sentido global. Não cabe dúvidas de que o mito seja uma forma de saber, que diz al go de algo e que, portanto, contém sentido e referência. ${ }^{34} \mathrm{C}$ omo saber narrado e vivido, os mitos são 0 fruto de um esforço de justificação do ser humano e da realidade na qual ele se encontra e se apreende como separado. O s mitos pretendem dar a chave do sentido da totalidade do ser humano que começa a despertar do seu sono de inocência, separando-se da unidade original. C omo diz Luis Cencillo,

o mito, antes de tudo, cria uma base de compreensão, em forma de esquemas mentais e de modelos gestálticos, para que 0 ser humano organize, dirija e ilumine a experiência bruta de si mesmo, do cosmo e dos acontecimentos eventuais (destino, providência, progresso, projeção escatológica etc...) nos quais o ser humano se vê envolvido e comprometido. Assim se vão formando, graças ao mito, umas constelações representativas e uns pontos de orientação estético-éticos capazes de sustentar a ausência de fundamento radical do ser humano e sua desorientação original em meio a uma realidade polivalente. ${ }^{35}$

Assim se vê que o mito, embora surgindo num universo précategorial e estático, prepara, na sua evolução, o advento do universo categorial e formalizado, por causa de uma espécie de dialética interna. A o mesmo tempo em que evoca uma realidade, ele mesmo não se esgota e não a esgota, porque a realidade a que ele al ude é "a totalidade sensata que, no homem, se revela a si mesma como sensata" ${ }^{36} 0$ sentido de total idade a que o mito se refere é constitutivo do próprio ser humano, desde a mais primitiva afirmação da sua humanidade e apresenta-se como a condição de possibilidade de 
toda experiência verdadeiramente humana. Eis também por que nenhum saber sobre o mito o esgota totalmente, pois

o mito nos oferece, sempre aludida, a plenitude e o sentido, de modo que toda atividade humana, até os menores gestos, aparecem carregados de significação e ligados a algo enormemente importante que se apresenta atrás de cada real idade. ${ }^{37}$

Enquanto atitude vivida que se traduz numa forma de discurso, o mito, como dissemos, éo antecedenteimediato de outra forma de expressão conhecida como literatura sapiencial. A literatura sapiencial parece inscrever-se no próprio coração do mito. Antes de dar ao homem conselhos, a sabedoria representa uma tentativa de exploração do universo com a finalidade de assumir e dominar a sua imensa diversidade. Nesse sentido, procedem dessa atividade exploratória as classificações de animais, de plantas, de pedras, assim como as classificações dos povos, dos acontecimentos e, mais precisamente, as classificações binárias (macho-fêmea, céu-terra, luztrevas, seres vivos-seres inanimados, espírito-corpo, selvagem-doméstico, puro-impuro, jardimestepe, árvore de vidaerva estéril etc.). D e modo geral, todas as tentativas de denominação das coisas criadas traduzem a relação do universo com a nossa forma de pensar.

Segundo Paul Ricoeur, a fronteira entre o mito e a sabedoria é muito tênue, a ponto de podermos dizer que a sabedoria faz conscientemente 0 que o mito faz inconscientemente. $\mathrm{N}$ ão se pode subestimar a força vital da atividade sapiencial na qual se depositam os resultados da atitude exploratória e da estrutura classificatória do modo primitivo de ser no mundo. É na sabedoria de vida dos grupos humanos que se sedimentam as posições ou decisões tomadas relativamente às ambigüidades da realidade: a semelhança e a diferença, o parentesco e a oposição, a continuidade e a discordância, 0 sim e 0 não, numa palavra, o bem e o mal. A busca do sentido recebe aqui uma dimensão mais existencial, porque é na medida em que o mundo aparece como um sentido ameaçado que a sabedoria adquire um alcance ético: conhecer o mundo é ser capaz de 
viver nele e nele afrontar o absurdo. Por isso os mitos da origem têm uma dimen são sapiencial, pois compreen der a origem das coisas é saber o seu significado atual e, também, o que elas continuarão a oferecer aos homens. 0 s mitos da queda, por sua vez, têm a função de restaurar um sentido numa situação de desordem, de ameaça e de incerteza. ${ }^{38}$

Assim, a sabedoria traduz o próprio coração do mito, na medida em que preten de responder as mesmas questões que fizeram a vida ultrapassar o limiar da humanidade, e que se resumem na questão do sentido ou, o que é o mesmo, na questão do bem. ${ }^{39}$ É na resposta a essas questões que o mito oferece um mundo significante para a experiência humana e desenvolve uma sabedoria para a vida.

Esta breve aproximação filosófica ao mito pretendia mostrar que a consciência mítica, surgida com o aparecimento do ser humano no mundo, não é uma consciência arcaica ou primitiva, no sentido pejorativo dos termos, que devia ser descartada com 0 advento e a soberania da razão raciocinante. Ao contrário, a consciência mítica é um dos níveis estruturais da consciência humana, que corresponde à primeira experiência do ser humano no mundo, que é sempre a experiência do seu enraizamento e da sua abertura para o sentido. A emergência da "idade da razão", com os fisiólogos e filósofos gregos, não aboliu definitivamente a "idade dos mitos".

M ircea Eliade observa:

Muito provavelmente 0 gênio grego foi impotente para exorcizar, pelos seus próprios meios, o pensamento mítico, mesmo que o último deus tivesse sido destronado e seus mitos degradados ao nível de contos de crianças. Pois, de um lado, 0 gênio filosófico grego aceitava o essencial do pensamento mítico, o eterno retorno das coisas, a visão cíclica da vida cósmica e humana, e o espírito grego não considerava que a história pudesse se tornar objeto de conhecimento. A física e a metafísica gregas desenvolveram alguns temas constitutivos do pensamento mítico: a importância da origem, da arché, o 
essencial que precede a existência humana, o papel decisivo da memória etc. ${ }^{40}$

Portanto, não há uma descontinuidade radical entre razão e mito, justamente porque são dois níveis estruturais da consciência humana. O smitos são indispen sáveis, tanto para os indivíduos como para as sociedades.

O s mitos são como a memória social, que assegura a reprodução dos comportamentos da espécie humana. A memória social, ou a memória-tradição, é biologicamente indispensável à espécie humana, desempenhando para ela a mesma função que desempenha o condicionamento genético nas sociedades animais. Como diz M arcel Detienne,

se o mito significa a memorabilidade numa cultura da palavra, então gêneros tão diferentes aos nossos olhos como as genealogias, os provérbios, as teogonias ou os contos são os produtos diferenciados da mesma memória social. ${ }^{41}$

N o que diz respeito aos indivíduos, assim como os sonhos são indispen sáveis para a saúde física e mental dos indivíduos, também os mitos são necessários para a atividade intelectual e para a organização das relações entre os indivíduos. Na medida em que os mitos servem para construir as categorias nas quais se enraizam as culturas, eles lançam ao mesmo tempo as bases da significação e da comunicação.

Concluo, portanto, com a mesma citação de A ristóteles, que apresentei como epígrafe a estas reflexões, para mostrar que, desde as origens, o pensamento fil osófico apreendeu, junto com a relação de concorrência, a relação de amizade existente entre mito e filosofia: "também aquele que ama o mito é, de certo modo, filósofo" (M etafísica, A 2, 982 b 18). 
model and the comprehension of the mythical conscience as originating form of the presence of the human being in the world reveal the myth as wisdom, by which the human groups guaranteed their survival and identity and upon which they formulate the sense of their existence.

Key words: M yth, Philosophy, narrative, metaphor, wisdom.

\section{Notas}

1. Aristóteles, Da alma, A 5, 411 a 8 =Diels-Kranz, 11 A 22 .

2. Sobre as raízes da filosofia nascente na mentalidade religiosa dos gregos ver JAEGER, W . La teología de los primeros filósofos griegos. Tradução de J. Gaos. Bogotá: Fondo de Cultura Económica, 1997.

3. Diels-Kranz, 22 B 32.

4. Cf. Zeller-M ondolfo, I, 4, p. 161, nota 82, apud Reale, G. H istória da filosofia antiga. v. I: Das origens a Sócrates. Tradução de M. Perine. São Paulo: Loyola, 1993, p. 68. N essa mesma linha de interpretação do fragmento 32 de H eráclito, ver também JAEGER, W., op. cit., p. 127

5. Sobre isso permanece uma referência indispensável a obra de Schelling, F. W. Einleitung in die Philosophieder M ythologie [1825] (Introduction à la philosophie de la mythologie. Tradução de S. Jankélévitch. Paris: Aubier, 1946).

6. Sobre Xenófanes, ver Reale, G. O p. cit., p. 97-105. Ver também JAEGER, W. O p. cit., p. 43-59.

7. Cf. Platão, República, II, 369 A e C.

8. Entre outros, o mito das cigarras no Fedro (258 E - 259 D) é, certamente, uma invenção de Platão.

9. Sobre o orfismo, ver Reale, G. Op. cit. p. 371-386. Sobre a componente religiosa do pensamento de Platão, ver REALE, G. H istória da filosofia antiga. v. II. Platão e A ristóteles. Tradução de H. C. de Lima Vaz e M. Perine. São Paulo: Loyola, 1994, especialmente p. 181ss. Sobre as lâminas de ouro órficas, ver 0 
recente trabalho de decifração, tradução e comentário de Giovanni Pugliesi Carratelli: Le lamine d'oro orfiche. Istruzioni per il viaggi o oltremondano degli iniziati greci. M ilão: A delphi, 2001.

10. Cf. Platão, Leis, II, 664 A.

11. Cf. Ramnoux, C. Mythe. Mythos et logos. Encyclopaedia U niversalis France, Corpus, v. 12, p. 881-883.

12. Cf. "M ythos". In G rande Lessico del Nuovo Testamento. Brescia 1971. Ver também O тто, W. F. E ssais sur le mythe. Tradução de P. David. M auvezin: Trans-Europ-Repress, 1987.

13. Para o que se segue ver RICOEUR, P. M ythe. Interprétation philosophique, Encyclopaedia U niversalis France, Corpus, v. 12, p. 883-886.

14. Esta é também a posição de Schelling. O p. cit., p. 238.

15. Sobre a interpretação alegórica do mito é fundamental a obra de PePin, J. M ythe et allégorie. Les origines grecques et les contestations judéo-chrétiennes. Paris: Études Augustiniennes, 1976.

16. Cf. SOREL, R. De l'interprétation du mythe. Encyclopédie Philosophique U niverselle. V. IV: Le discours philosophique. Volume dirigé par Jean-François Mattéi. Paris: PU F, 1998. p. 1498-1512, especialmente p. 1499-1502.

17. Cf. Ricoeur, P. Temps et récit. Paris, 1983, 1984. 2 v.

18. Cf. Van Riet, G. Problèmes d'épistemologie. Lovaina, 1960. p. 345422.

19. Cf. Lévi-Strauss, C. A nthropologie structurale. Paris: Plon, 1958; La pensée sauvage. Paris: Plon, 1962; M ythologiques. Paris: Plon, 1964-1970. 4 v.

20. A obra fundamental de Saussure é o C ours de linguistique générale, publicado postumamente em 1916 por C. Baillye A. Sechehaye. Ver também Benveniste, É. Problèmes de linguistique générale. Paris: Gallimard, 1966. 
21. Cf. Ricoeur, P. Mythe. Interprétation philosophique. Op. cit., p. $884 \mathrm{~s}$.

22. Para um aprofundamento sobre o tema remeto ao pouco conhecido volume organizado por Sheldon Sachs e traduzido pela Educ, com comunicações e debates deum simpósio realizado em fevereiro de 1978 na U niversidade de C hicago, no qual se destaca um belo texto de Paul Ricoeur "O processo metafórico como cognição, imaginação e sentimento" (p. 145-160). Cf. SACHS, S. Da metáfora. Tradução de Leila C ristina M. Darin et al. São Paulo: Educ: Pontes, 1992. A posição de Ricoeur encontrase amplamente desenvolvida no seu La métaphore vive, cuja primeira edição é de 1975. Cf. RıcoeuR, P. A metáfora viva. Tradução de Dion D. M acedo. São Paulo: Loyola, 2000.

23. Para todo o desenvolvimento anterior, ver: RICOEUR, P. M ythe. Interprétation philosophique. 0 p. cit., p. $885 \mathrm{~s}$.

24. Cf. Eliade, M. Le mythe del'éternel retour. Paris: G allimard, 1949.

25. Cf. Ricoeur, P. Mythe. Interprétation philosophique. O p. cit., p. 887.

26. Cf. O тто, R. Le sacré. L'élement non rationnel dans l'idée du divin et sa relation avec le rationnel. Tradução de P. Jundt. Paris: Payot, 1929.

27. Cf. Lıma V Az, H . C. O ntologia ehistória. São Paulo: Loyola, 2001 (1.ed. São Paulo: Duas Cidades, 1968), particularmente o cap. XI: "O absoluto ea história", p. 247-278.

28. Cf. GUSDORF, G. M ythe et métaphysique. Introduction à la philosophie. Paris: Flamarion, 1953 (2.ed. 1984).

29. Cf. Ricoeur, P. La symbolique du mal. Paris: Aubier, 1961.

30. Cf. ElIAde, M. O p. cit., p. 86.

31. Cf. Gusdorf, G. O p. cit., p. 31.

32. Cf. Van Der Leeuw, G. Fenomenología dela religión. M éxico: Fondo de Cultura Económica, 1964. p. 398. 
33. Cf. Van Der Leeuw, G. O p. cit., p. 399.

34. Cf. Cencillo, L. M ito. Semántica y realidad. Madrid, 1970. p. 438.

35. Cf. Cencillo, L. O p. cit., p. 439.

36. Cf. W EIL, E. De la réalité. Essais et conférences. Paris: Plon, 1970. p. 318.

37. Cf. Cencillo, L. O p. cit., p. 449.

38. Cf. RICOeUR, P. Mythe. Interprétation philosophique. 0 p. cit., p. 888.

39. Cf. W EIL, E. Philosophie morale. Paris: Vrin, 1969. p. 18-20.

40. Cf. Eliade, M. Aspects du mythe. Paris: Gallimard, 1963. p. 140.

41. Cf. Detienne, M. M ythes. Épistémologie des mythes, Encyclopaedia U niversalis France, Corpus, v. 12, p. 890-895, aqui p. 895.

\section{Referênaias}

Benveniste, É. Problèmes de linguistique générale. Paris: Gallimard, 1966.

Carratelli, G. P. (Ed.). Lelamined'oro orfiche. Istrużoni per il viaggio oltremondano degli iniziati greci. Milão: Adelphi, 2001.

Cencillo, L. M ito. Semántica y realidad. Madri, 1970.

Detienne, M. Mythes. Épistémologie des mythes, Encyclopaedia U niversalis France, Corpus, v. 12, p. 890-895.

EliAde, M. Le mythe de l'éternel retour. Paris: Gallimard, 1949.

. A spects du mythe. Paris: Gallimard, 1963.

Grande Lessico del Nuovo Testamento. Brescia, 1971.

GuSDORF, G. M ythe et métaphysique. Introduction à la philosophie. Paris: Flamarion, 1953 (2.ed. 1984).

JAEGER, W. La teología de los primeros filósofos griegos. Tradução de J. Gaos. Bogotá: Fondo de Cultura Económica, 1997. 
Lévi-Strauss, C. A nthropologie structurale. Paris: Plon, 1958.

- La pensée sauvage. Paris: Plon, 1962.

. M ythologiques. 4 v., Paris: Plon, 1964-1970.

Lıma VAz, H. C. 0 ntologia e história. São Paulo: Loyola, 2001. (1.ed. São Paulo: Duas Cidades, 1968).

O тто, R. Le sacré. L'élement non rationnel dans l'idée du divin et sa relation avec le rationnel. Tradução de P. Jundt. Paris: Payot, 1929.

O тто, W. F. Essais sur le mythe. Tradução de P. David. Mauvezin: Trans-Europ-Repress, 1987.

PEPIN, J. M ythe et allégorie. Les origines grecques et les contestations judéo-chrétiennes. Paris: Études Augustiniennes, 1976.

Ramnoux, C. Mythe. Mythos et logos. Encyclopaedia U niversalis France, Corpus, v. 12, p. 881-883.

Reale, G. H istória da filosofia antiga. I. Das origens a Sócrates. Tradução de M. Perine. São Paulo: Loyola, 1993.

. H istória da filosofia antiga. II. Platão e A ristóteles. Tradução de H. C. de Lima Vaze M. Perine. São Paulo: Loyola, 1994.

Ricoeur, P. Mythe. Interprétation philosophique, Encyclopaedia U niversalis France, Corpus, v. 12, p. 883-886.

. La symbolique du mal. Paris: Aubier, 1961.

- Temps et récit. 2 v. Paris, 1983, 1984.

A metáfora viva. Tradução de Dion D. Macedo. São Paulo: Loyola, 2000.

SACHS, S. Da metáfora. Tradução de Leila Cristina M. Darin et al. São Paulo: Educ: Pontes, 1992.

SCHeLLIN G, F. W. Introduction à la philosophie dela mythologie. Tradução de S. Jankélévitch. Paris: Aubier, 1946. 
So ReL, R. De l'interprétation du mythe. Encyclopédie Philosophique U niverselle. IV. Le discours philosophique. Volume dirigé par JeanFrançois M attéi. Paris: PU F, 1998. p. 1498-1512.

Van Der Leeuw, G. Fenomenología de la religión. M éxico: Fondo de Cultura Económica, 1964.

V AN RIET, G. Problèmes d'épistemologie. Lovaina, 1960.

W EIL, E. De la réalité. Essais et conférences I. Paris: Plon, 1970. . Philosophie morale. Paris: Vrin, 1969. 